\title{
Bronchial reversibility with a short-acting $\beta 2$-agonist predicts the FEV1 response to administration of a long-acting $\beta 2$-agonist with inhaled corticosteroids in patients with bronchial asthma
}

\author{
AKIHIKO OHWADA ${ }^{1,2}$, KEI INAMI ${ }^{2}$, EMI ONUMA ${ }^{2}$, MARIKO MATSUMOTO-YAMAZAKI $^{2}$, \\ RYO ATSUTA $^{2}$ and KAZUHISA TAKAHASHI ${ }^{2}$
}

${ }^{1}$ Ohwada Clinic, Chiba; ${ }^{2}$ Department of Respiratory Medicine, Juntendo University School of Medicine, Tokyo, Japan

Received April 1, 2011; Accepted May 3, 2011

DOI: $10.3892 / \mathrm{etm} .2011 .268$

\begin{abstract}
A long-acting $\beta 2$-agonist (LABA) combined with an inhaled corticosteroid (ICS) is frequently prescribed as initial therapy in steroid-naïve asthma patients because of its effective control of symptoms and improvement of pulmonary function. However, it is unclear which patients will be responsive to LABAs and whether bronchial responsiveness to LABAs is similar to that to short-acting $\beta 2$-agonists (SABAs) in a clinical setting. Therefore, the goal of the present study was to compare the changes in spirometric parameters after SABA (salbutamol) inhalation to those after 1-month LABA/ ICS (salmeterol/fluticasone propionate) therapy. Spirometric changes were evaluated as absolute values, as the percentage of predicted normal values and as the percentage of baseline values after salbutamol inhalation or 1-month LABA/ICS therapy in 45 patients with asthma. Compared to SABA inhalation, LABA/ICS therapy produced significant improvements in forced expiratory volume in $1 \mathrm{sec}$ (FEV1), peak expiratory flow (PEF), forced expiratory flow at $50 \%$ of vital capacity expired (FEF50\%) from baseline (expressed as the percentage predicted) in all patients. FEV1 and the FEV1/forced vital capacity (FVC) ratio after SABA or LABA/ICS therapy were inversely related to the corresponding baseline values. Analysis of spirometric changes after SABA inhalation showed that FEV1 was the best among spirometric parameters, such as PEF, correlated with responsiveness to LABA/ ICS therapy. Reversibility of FEV1 with SABA inhalation predicts the spirometric response to LABA/ICS as initial therapy in patients with bronchial asthma. LABA/ICS therapy had a greater effect on bronchial reversibility in asthmatic patients, compared to SABA inhalation. This suggested that evaluation of bronchial reversibility after LABA/ICS therapy would be superior to that after SABA inhalation.
\end{abstract}

Correspondence to: Dr Akihiko Ohwada, Ohwada Clinic, 4-7-13 Minamiyawata, Ichikawa, Chiba 272-0023, Japan

E-mail: aohwada@hotmail.co.jp

Key words: bronchial asthma, short-acting $\beta 2$-agonist, long-acting $\beta 2$-agonist, bronchial reversibility, lung function test

\section{Introduction}

Bronchial asthma is a common respiratory disease encountered at outpatient clinics, and is characterized by reversible airflow obstruction and airway hyperresponsiveness (1). Comparison of the values of the baseline forced expiratory volume in $1 \mathrm{sec}$ (FEV1) before and after inhalation of a short-acting 32 -agonist (SABA) is a simple and cost-effective method for evaluation of the reversibility of airflow obstruction that can be performed at outpatient clinics.

In steroid-naïve adult patients with asthma, Ni Chroinin et al found that first-line therapy with a long-acting $\beta 2$-agonist (LABA) combined with an inhaled corticosteroid (ICS) did not significantly reduce the risk of exacerbation that requires rescue oral corticosteroids, compared to a similar dose of ICS alone (2). On the other hand, this analysis revealed that the LABA/ICS combination significantly improved lung function and reduced symptoms (2), and these effects are likely to motivate asthmatic patients to continue inhalation therapy. However, it is unclear which patients respond to LABA/ ICS inhalation. Therefore, the present study was performed prospectively to identify the spirometric parameter measured after SABA inhalation that most effectively predicts improvement in bronchodilation after LABA/ICS therapy.

\section{Patients and methods}

Selection of patients. The subjects were selected randomly among non-smoking patients who were diagnosed with bronchial asthma at their initial visit. All patients had cough, accompanied with at least one of the symptoms, including dyspnea, wheezing, repeated episodes of prolonged cough, positive history of childhood asthma, atopic diathesis and family history of bronchial asthma. None of the patients had taken inhaled steroids or $\beta 2$ agonists for at least 3 months before the examination. Spirometry was performed with a Microspiro HI-801 (Chest Inc., Nihon Kohden, Japan) following the instructions in the ATS guidelines, and the highest FEV1 value of three recordings was taken (3-5). The FEV1, peak expiratory flow (PEF), forced expiratory flow at $50 \%$ of vital capacity (VC) expired (FEF50\%), forced expiratory flow at $75 \%$ of VC expired (FEF75\%), forced 
expiratory flow between 25 and $75 \%$ of VC (FEF25-75\%), and the FEV1/forced vital capacity (FVC) ratio were measured (3-5). These parameters are presented as absolute values and percentiles of the predicted values (percentage predicted). Reversibility of airflow limitation was evaluated with FEV1 and other spirometric parameters at $15 \mathrm{~min}$ after inhalation of $200 \mu \mathrm{g}$ of a SABA, salbutamol, using a spacer (3-5). Salmeterol/fluticasone propionate (LABA/ICS) in combination was then prescribed at a dose of $50 / 250 \mu \mathrm{g}$ twice a day for 1 month. All patients who took the SABA reversibility test were asked to visit again after 1 month of LABA/ICS therapy for re-evaluation with spirometry. Since PEF is known to vary within 1 day, the patients were asked to visit at a similar time as the initial visit. Changes after SABA inhalation and LABA/ ICS therapy were expressed as absolute values, percentage predicted and percentage baseline. The percent changes from baseline were calculated by subtracting baseline values from post-bronchodilator values and then dividing the difference by baseline values. All patients provided informed consent. The study was approved by the Ethics Committee of Juntendo University.

Statistical analysis. Data are presented as the means \pm SD. Analyses were performed by the non-parametric Mann-Whitney t-test for comparison between baseline and post-bronchodilator values, and correlation coefficients were calculated by the
Table I. Characteristics of the subjects.

\begin{tabular}{lc}
\hline Characteristics & Value \\
\hline No. & 45 \\
Age, mean (years) & $36.8 \pm 10.2$ \\
Male & 12 \\
Female & 33 \\
Symptoms/signs & \\
Wheezing & 5 \\
Dyspnea & 10 \\
Repeated cough for $>4$ weeks & 19 \\
Past history of asthma & 11 \\
Allergic diathesis & 13 \\
Family history of asthma & 8 \\
\hline
\end{tabular}

non-parametric Spearman method, using Graphpad Prism (Graphpad Software, Inc., San Diego, CA, USA). A p-value of $<0.05$ was considered to indicate a significant difference.

\section{Results}

Spirometric response after SABA inhalation and LABA/ICS therapy. Forty-five patients between 17 and 62 years of age

Table II. Spirometric changes after SABA or LABA/ICS inhalation.

\begin{tabular}{|c|c|c|c|c|c|c|}
\hline & Absolute values & p-value & & Percentage predicted & p-value & \\
\hline \multicolumn{7}{|l|}{ FEV1 } \\
\hline Baseline & $2.72 \pm 0.69$ & & & $88.96 \pm 13.12$ & & \\
\hline SABA & $2.85 \pm 0.68$ & 0.362 & ns & $93.39 \pm 12.86$ & 0.069 & ns \\
\hline LABA/ICS & $2.92 \pm 0.64$ & 0.148 & ns & $96.01 \pm 11.19$ & 0.010 & $* *$ \\
\hline \multicolumn{7}{|l|}{ PEF } \\
\hline Baseline & $5.93 \pm 1.75$ & & & $68.53 \pm 15.07$ & & \\
\hline SABA & $5.98 \pm 1.97$ & 0.897 & $\mathrm{~ns}$ & $68.71 \pm 16.25$ & 0.994 & ns \\
\hline LABA/ICS & $6.78 \pm 2.00$ & 0.040 & $*$ & $78.02 \pm 15.74$ & 0.004 & $* *$ \\
\hline \multicolumn{7}{|l|}{ FEF50\% } \\
\hline Baseline & $3.13 \pm 1.12$ & & & $64.44 \pm 20.02$ & & \\
\hline SABA & $3.53 \pm 1.22$ & 0.125 & ns & $72.63 \pm 21.02$ & 0.069 & ns \\
\hline LABA/ICS & $3.63 \pm 1.37$ & 0.089 & ns & $74.37 \pm 23.55$ & 0.049 & $*$ \\
\hline \multicolumn{7}{|l|}{ FEF75\% } \\
\hline Baseline & $1.35 \pm 0.75$ & & & $51.57 \pm 23.64$ & & \\
\hline SABA & $1.54 \pm 0.84$ & 0.292 & ns & $58.78 \pm 26.15$ & 0.168 & ns \\
\hline LABA/ICS & $1.53 \pm 0.76$ & 0.207 & ns & $58.28 \pm 23.68$ & 0.149 & ns \\
\hline \multicolumn{7}{|l|}{ FEF $25-75 \%$} \\
\hline Baseline & $2.73 \pm 1.07$ & & & $69.61 \pm 21.83$ & & \\
\hline SABA & $3.00 \pm 1.17$ & 0.274 & ns & $76.33 \pm 22.55$ & 0.213 & ns \\
\hline LABA/ICS & $3.13 \pm 1.22$ & 0.103 & ns & $79.22 \pm 23.94$ & 0.056 & ns \\
\hline \multicolumn{7}{|c|}{ FEV1/FVC ratio } \\
\hline Baseline & $80.47 \pm 8.86$ & & & & & \\
\hline SABA & $82.05 \pm 8.34$ & 0.460 & ns & & & \\
\hline LABA/ICS & $83.82 \pm 7.81$ & 0.086 & ns & & & \\
\hline
\end{tabular}

p-value indicates statistical significance between values at baseline and after SABA inhalation or LABA/ICS therapy. ns, no significance; $*, \mathrm{p}<0.05 ; * *, \mathrm{p}<0.01$. 
Table III. Correlation of spirometric parameters between baseline values and changes after SABA or LABA/ICS inhalation.

\begin{tabular}{|c|c|c|c|c|c|c|c|c|}
\hline & \multicolumn{3}{|c|}{ SABA } & & \multicolumn{3}{|c|}{ LABA/ICS } & \\
\hline & Values & $\mathrm{r}$ & p-value & & Values & $\mathrm{r}$ & p-value & \\
\hline \multicolumn{9}{|l|}{ FEV1 } \\
\hline Change, absolute & $0.13 \pm 0.19$ & -0.234 & 0.122 & ns & $0.20 \pm 0.29$ & -0.359 & 0.016 & $*$ \\
\hline Change, $\%$ predicted & $4.44 \pm 6.44$ & -0.339 & 0.023 & $*$ & $7.05 \pm 9.91$ & -0.476 & 0.001 & $* * *$ \\
\hline Change, $\%$ baseline & $5.46 \pm 8.13$ & -0.416 & 0.004 & $* *$ & $9.15 \pm 13.98$ & -0.446 & 0.002 & $* *$ \\
\hline \multicolumn{9}{|l|}{$\mathrm{PEF}$} \\
\hline Change, absolute & $0.05 \pm 0.96$ & 0.003 & 0.987 & ns & $0.86 \pm 1.12$ & 0.003 & 0.985 & ns \\
\hline Change, $\%$ predicted & $0.18 \pm 10.47$ & -0.146 & 0.337 & ns & $9.50 \pm 11.75$ & -0.275 & 0.677 & ns \\
\hline Change, $\%$ baseline & $1.02 \pm 15.82$ & 0.049 & 0.749 & ns & $16.08 \pm 21.30$ & -0.127 & 0.405 & ns \\
\hline \multicolumn{9}{|l|}{ FEF50\% } \\
\hline Change, absolute & $0.41 \pm 0.50$ & 0.024 & 0.878 & ns & $0.51 \pm 0.75$ & 0.095 & 0.534 & ns \\
\hline Change, $\%$ predicted & $15.36 \pm 18.79$ & -0.445 & 0.002 & $* *$ & $9.93 \pm 14.80$ & -0.079 & 0.606 & ns \\
\hline Change, $\%$ baseline & $33.30 \pm 48.90$ & -0.478 & 0.001 & $* *$ & $17.80 \pm 25.42$ & -0.110 & 0.471 & ns \\
\hline \multicolumn{9}{|l|}{ FEF75\% } \\
\hline Change, absolute & $0.19 \pm 0.30$ & -0.235 & 0.120 & ns & $0.18 \pm 0.46$ & -0.235 & 0.120 & $\mathrm{~ns}$ \\
\hline Change, $\%$ predicted & $7.21 \pm 11.66$ & -0.341 & 0.022 & $*$ & $6.71 \pm 17.03$ & -0.341 & 0.022 & $*$ \\
\hline Change, $\%$ baseline & $16.83 \pm 24.22$ & -0.174 & 0.253 & ns & $19.69 \pm 38.94$ & -0.317 & 0.034 & $*$ \\
\hline \multicolumn{9}{|l|}{ FEF $25-75 \%$} \\
\hline Change, absolute & $0.27 \pm 0.41$ & 0.066 & 0.666 & ns & $0.40 \pm 0.62$ & 0.056 & 0.715 & ns \\
\hline Change, $\%$ predicted & $6.72 \pm 10.45$ & -0.111 & 0.467 & ns & $9.61 \pm 14.88$ & -0.177 & 0.246 & ns \\
\hline Change, $\%$ baseline & $6.72 \pm 10.45$ & -0.283 & 0.060 & ns & $16.48 \pm 25.43$ & -0.123 & 0.421 & ns \\
\hline \multicolumn{9}{|l|}{ FEV1/FVC ratio } \\
\hline Change, absolute & $1.59 \pm 3.27$ & -0.337 & 0.024 & $*$ & $3.36 \pm 6.12$ & -0.481 & 0.001 & $* * *$ \\
\hline Change, $\%$ baseline & $2.16 \pm 4.26$ & -0.391 & 0.008 & $*$ & $4.68 \pm 8.46$ & -0.521 & 0.0001 & $* * *$ \\
\hline
\end{tabular}

ns, no significance; $*, \mathrm{p}<0.05 ; * *, \mathrm{p}<0.01 ; * * *, \mathrm{p}<0.001$.

were eligible for comparison of baseline spirometric parameters with those values after inhalation of both SABA and LABA/ ICS (Table I). Five patients had audible wheezing at the initial examination, 10 had dyspnea at the first visit, 19 had experienced episodes of repeated cough lasting $>4$ weeks, 11 had a history of childhood asthma, 13 had allergic diathesis and 8 had a family history of asthma.

The baseline FEV1 values in all patients were $2.72 \pm 0.69$ liters and $88.96 \pm 13.12 \%$ predicted (Table II). The baseline values of PEF, FEF50\%, FEF75\% and FEF $25-75 \%$ were $68.53 \pm 15.07,64.44 \pm 20.02,51.57 \pm 23.64$ and $69.61 \pm 21.83 \%$ predicted, respectively (Table II). These low values indicate the presence of large and small airflow obstructions (3-6). The baseline FEV1/FVC ratio was $80.47 \pm 8.86 \%$.

FEV1 after SABA (salbutamol) inhalation was $2.85 \pm 0.68$ liters and $93.39 \pm 12.86 \%$ predicted, with no significant difference with the respective baseline values $(p=0.362$ and 0.069 , respectively) (Table II). There was also no improvement in PEF, FEF50\%, FEF75\%, FEF25-75\% and the FEV1/ FVC ratio after inhalation of SABA compared to baseline values (Table II).

To examine whether LABA/ICS therapy improved lung function, spirometric results after the 1-month treatment were compared to baseline values. The re-evaluation by spirometry was performed at a mean of $29.7 \pm 3.9$ days after initiation of LABA/ICS therapy. FEV1 values after 1 month of LABA/ICS therapy were $2.92 \pm 0.64$ liters and $96.01 \pm 11.19 \%$ predicted. The percent predicted value was significantly higher than the baseline FEV1 $(\mathrm{p}=0.010)$ (Table II). PEF values after LABA/ ICS therapy $(6.78 \pm 2.00$ liters/sec and $78.02 \pm 15.74 \%$ predicted) were both higher than the baseline values $(\mathrm{p}=0.040$ and 0.004 , respectively) (Table II). FEF50\% (percentage predicted) after LABA/ICS therapy was also higher than baseline FEF50\% $(p=0.049)$. These improvements in spirometric parameters were not observed after SABA inhalation, indicating that LABA/ICS therapy had a greater effect on improving bronchodilation in the patients. FEF75\%, EF25-75\% and the FEV1/FVC ratio were not significantly improved after LABA/ ICS inhalation (Table II).

Relationships of baseline values with response after SABA and $L A B A / I C S$ therapy. Relationships between baseline values and changes after SABA inhalation or LABA/ ICS therapy were evaluated. Increases in FEV1 from the respective baseline values after SABA inhalation (salbutamol) were $0.13 \pm 0.19$ liters, $4.44 \pm 6.44 \%$ predicted and $5.46 \pm 8.13 \%$ baseline. The changes in FEV1 from baseline values after LABA/ICS inhalation were $0.20 \pm 0.29$ liters, $7.05 \pm 9.91 \%$ predicted and $9.15 \pm 13.98 \%$ baseline. FEV1 after SABA inhalation increased substantially when the baseline value was low, giving a significantly negative correlation $(r=-0.416$, $\mathrm{p}=0.004$ for percentage baseline) (Table III). FEV1 also 
improved after LABA/ICS therapy, with a more significant inverse correlation $(\mathrm{r}=-0.446, \mathrm{p}=0.002$ for percentage baseline) (Table III). FEF50\% after SABA inhalation and the FEV1/FVC ratio after LABA/ICS therapy also improved, with significant negative correlations with baseline values. This tendency was not observed for PEF.

Correlation of spirometric responses after SABA and LABA/ ICS inhalation. Correlation analysis revealed that SABA responsiveness based on FEV1 was significantly related to LABA/ICS responsiveness based on FEV1 for all three data types $(\mathrm{r}=0.541, \mathrm{p}=0.0001$ for absolute values, $\mathrm{r}=0.549$, $\mathrm{p}<0.0001$ for percentage predicted, $\mathrm{r}=0.635, \mathrm{p}<0.0001$ for percentage baseline) (Table IV). PEF and the FEV1/FVC ratio gave weak, but significant correlations for SABA and LABA/ ICS responsiveness, whereas no correlation was obtained for FEF75\% and FEF25-75\% (Table IV).

\section{Discussion}

Nelson et al first suggested that monotherapy with LABAs should be avoided because of increased risks of asthma exacerbation, hospitalization and asthma-related death in a subpopulation of patients (7). Following this study, prescription of LABAs has been recommended as 'add-on' medicine to ICS in adult asthmatic patients. This add-on policy has led to limited usage of LABAs, which are added only for patients in whom asthma is inadequately controlled by ICS alone, with prompt withdrawal of the LABA after control is achieved (8). However, many studies have found no problems with the use of LABAs in combination with ICS.

LABA/ICS combinations are not recommended as firstline therapy $(1,2)$, but it is not uncommon for this combination to be administered as an initial therapy in practice because of its superiority for relief of symptoms and improvement of lung function, compared to ICS alone (2). Since 2002, prescription of salmeterol in a LABA/ICS combination has been permitted in Japan, and a salmeterol/fluticasone propionate combination in a single inhaler (Adoair, GlaxoSmithKline) has been available since 2007. A formoterol/budesonide combination (Symbicort, AstraZeneca) was introduced in Japan in 2010. Epidemiologic analysis has shown that the number of asthmarelated deaths has continued to decline in Japan after the introduction and increased use of salmeterol, as also observed in European countries $(9,10)$.

In this study, we first evaluated spirometry after SABA inhalation in 45 asthmatic patients and found no significant increases in FEV1, PEF, FEF50\%, FEF75\%, FEF25-75\% and the FEV1/FVC ratio (Table II). By contrast, significant improvements in FEV1, PEF and FEF50\% were observed in the same patients after 1 month of LABA/ICS therapy. FEV1 was significantly improved after SABA inhalation and LABA/ICS therapy, with an inverse correlation with baseline FEV1 (Table III), as also found by Brand et al (11). In correlation analysis of spirometric changes reflecting responsiveness to SABA and LABA/ICS, FEV1 had the most significant coefficients for both therapies (Table IV).

SABAs and LABAs are pharmacologically similar, except for their speed and duration of action (12), but few reports have compared the effectiveness of these drug classes for
Table IV. Correlation of spirometric responsiveness between SABA and LABA/ICS inhalation.

\begin{tabular}{lccc}
\hline & $\mathrm{r}$ & $\mathrm{p}$-value & \\
\hline FEV1 & & & \\
Change, absolute & 0.541 & 0.0001 & $* * *$ \\
Change, \% predicted & 0.549 & $<0.0001$ & $* * *$ \\
Change, \% baseline & 0.635 & $<0.0001$ & $* * *$ \\
PEF & & & \\
Change, absolute & 0.328 & 0.028 & $*$ \\
Change, \% predicted & 0.351 & 0.018 & $*$ \\
Change, \% baseline & 0.299 & 0.046 & $*$ \\
FEF50\% & & & \\
Change, absolute & 0.419 & 0.004 & $* *$ \\
Change, \% predicted & 0.266 & 0.077 & $\mathrm{~ns}$ \\
Change, \% baseline & 0.374 & 0.011 & $*$ \\
FEF75\% & & & \\
Change, absolute & 0.233 & 0.123 & $\mathrm{~ns}$ \\
Change, \% predicted & 0.275 & 0.067 & $\mathrm{~ns}$ \\
Change, \% baseline & 0.317 & 0.034 & $\mathrm{~ns}$ \\
FEF25-75\% & & & \\
Change, absolute & 0.104 & 0.224 & $\mathrm{~ns}$ \\
Change, \% predicted & 0.160 & 0.295 & $\mathrm{~ns}$ \\
Change, \% baseline & 0.206 & 0.175 & $\mathrm{~ns}$ \\
FEV1/FVC ratio & & & \\
Change, \% predicted & 0.330 & 0.027 & $*$ \\
Change, \% baseline & 0.354 & 0.017 & $*$ \\
\hline
\end{tabular}

ns, no significance.

improvement of pulmonary function parameters, such as FEV1, in a clinical setting. Furthermore, there is no method to predict responsiveness to first-line LABA/ICS combination therapy in steroid-naïve asthmatic patients. Our data indicated that bronchial reversibility assessed by FEV1 after SABA inhalation predicts the FEV1 response to LABA/ICS therapy in patients with bronchial asthma. Moreover, responsiveness after LABA/ICS therapy was higher than that after SABA inhalation. One concern with this finding is that the dose of SABA we chose may have been insufficient. Bronchial reversibility is defined as a SABA-induced increase in FEV1 of $\geq 0.20$ liters and $\geq 12 \%$ baseline. In our study, 9 of 45 patients (20\%) showed positive results after SABA inhalation at a dose of $200 \mu \mathrm{g}$ (data not shown). Application of the same criteria for bronchial reversibility after LABA/ICS therapy indicated a positive response in 13 of 45 patients (28.8\%) (data not shown). These results suggest that the dose of SABA was not particularly low, based on comparison to the positive rate after LABA/ICS therapy. Another possible explanation is that a LABA/ICS combination inhaler may have synergistic effects between the drugs, even though an ICS is not directly effective as a bronchodilator.

We were concerned about the relatively low rate of bronchial reversibility after SABA inhalation in our study. Yancey and Ortega showed that patients with a baseline FEV1 of $40 \%$ predicted to $<50 \%$ predicted at screening had a mean 
reversibility of $42 \%$, and those with a baseline FEV1 of $90 \%$ predicted to $<100 \%$ predicted had a mean reversibility of $18 \%$, with the conclusion that the lower the baseline lung function, the higher the reversibility (13). This is consistent with our observation that responsiveness after SABA or LABA/ ICS inhalation was inversely correlated with baseline FEV1 (Table III).

In conclusion, our study showed that FEV1 evaluation of bronchial reversibility by a SABA was predictive of the FEV1 response to a LABA/ICS in patients with bronchial asthma. Reversibility of airway obstruction after 1 month of LABA/ ICS therapy was superior to that after SABA inhalation.

\section{Acknowledgements}

The authors are grateful to Dr Yuko Tsutsumi-Ishii (Juntendo University School of Medicine) for the discussion of statistical analysis.

\section{References}

1. Global Initiative for Asthma (GINA): Global strategy for asthma management and prevention. NHLBI/WHO Workshop Report Bethesda: National Institutes of Health, National Heart, Lung and Blood Institute, Upgrade 2009.

2. Ni Chroinin M, Greenstone I, Lasserson TJ and Ducharme FM: Addition of inhaled long-acting beta2-agonists to inhaled steroids as first line therapy for persistent asthma in steroid-naive adults and children. Cochrane Database Syst Rev 7: CD005307, 2009.
3. Pellegrino R, Viegi G, Brusasco V, et al: Interpretative strategies for lung function tests. Eur Respir J 26: 948-968, 2005.

4. Miller MR, Hankinson J, Brusasco V, et al: Standardisation of spirometry. Eur Respir J 26: 319-338, 2005

5. American Thoracic Society: Lung function testing: selection of reference values and interpretative strategies. Am Rev Respir Dis 144: 1202-1218, 1991.

6. Lehtimäki L, Kankaanranta H, Saarelainen S, Turjanmaa V and Moilanen E: Peripheral inflammation in patients with asthmatic symptoms but normal lung function. J Asthma 42: 605-609, 2005.

7. Nelson HS, Weiss ST, Bleecker ER, Yancey SW, Dorinsky PM; SMART Study Group: The Salmeterol Multicenter Asthma Research Trial: a comparison of usual pharmacotherapy for asthma or usual pharmacotherapy plus salmeterol. Chest 129: 15-26, 2006.

8. Chowdhury BA and Pan GD: The FDA and safe use of longacting beta-agonists in the treatment of asthma. $\mathrm{N}$ Engl J Med 362: 1169-1171, 2010.

9. Dobashi K: Epidemiology of asthma. Igaku-No-Ayumi 233: 5-12, 2010 (In Japanese).

10. Chatenoud L, Malvezzi M, Pitrelli A, La Vecchia C and Bamfi F: Asthma mortality and long-acting beta2-agonists in five major European countries, 1994-2004. J Asthma 46: 546-551, 2009.

11. Brand PL, Quanjer PH, Postma DS, et al: Interpretation of bronchodilator response in patients with obstructive airways disease. The Dutch Chronic Non-Specific Lung Disease (CNSLD) Study Group. Thorax 47: 429-436, 1992

12. Beach JR, Young CL, Stenton SC, Avery AJ, Walters EH and Hendrick DJ: A comparison of the speeds of action of salmeterol and salbutamol in reversing methacholine-induced bronchoconstriction. Pulm Pharmacol 5: 133-135, 1992.

13. Yancey SW and Ortega HG: Retrospective characterization of airway reversibility in patients with asthma responsive to bronchodilators. Curr Med Res Opin 23: 3205-3207, 2007. 